\title{
Revisiting Childhood Herpes Zoster
}

\author{
Arjen F. Nikkels, M.D., Ph.D., ${ }^{* \dagger}$ Nazli Nikkels-Tassoudji, M.D., $\dagger$ and \\ Gérald E. Piérard, M.D., Ph.D.* \\ *Department of Dermatopathology, University Medical Center of Liège, Liège, Belgium, and \\ $\dagger$ Dermatology Division, St. Josef Klinik, St-Vith, Belgium
}

\begin{abstract}
Herpes zoster is rare in otherwise healthy children, but it is more common in association with immunosuppression. Maternal varicella infection during pregnancy and varicella occurring in the newborn represent risk factors for childhood herpes zoster. However, some controversies persist about risk factors, diagnosis, and the natural history of childhood disease. In a 2-year prospective study, 18 children with herpes zoster were clinically diagnosed in outpatient consultations in a hospital dermatology unit. Data about age, dermatome involvement, underlying disease, and history of previous varicella were recorded.Tzanck smears, biopsy specimens, and sera were obtained from 18, 4, and 10 children, respectively. The varicella zoster virus major envelope glycoprotein gE was detected in 16 of 18 smears and all four biopsies. Herpes simplex virus I was demonstrated in one of the smears. The established risk factors for childhood herpes zoster were only found in one child. Evidence for previous full-blown varicella and varicella with few lesions was recorded in 7 and 4 of the 17 immunocompetent children, respectively. No history of varicella was recalled in 6 of 17 cases, although a serologic clue of past varicella infection (IgM negative, IgG positive) was disclosed. Recurrent herpes zoster was diagnosed in one immunocompromised child. Zoster-associated pain was localized and the disease severity remained mild in all children. Established risk factors for childhood herpes zoster were only rarely found in our series of patients. In contrast, unrecognized varicella and varicella with few lesions were frequently recorded and may represent additional risk factors for shingles in childhood. Zosteriform herpes simplex virus infections should be differentiated from childhood herpes zoster, emphasizing the importance of precise viral identification.
\end{abstract}

Herpes zoster results from the reactivation of the varicella-zoster virus (VZV). It usually affects elderly patients (1-3). More rarely, shingles may occur in immunocompromised (4-12) and immunocompetent children (9,11-25). The disease affects about $0.07 \%$ of children who are organ recipients or have malignancies at less than 9 years of age (1,26-29). Childhood herpes zoster is seldom associated with unrecognized malignancy (30), but about $3 \%$ of cases correspond to identified cancers in children (31). In these patients, the disease course is similar to that of adult herpes zoster (32). During the past decades, herpes zoster has been identified

Address correspondence to A. F. Nikkels, M.D., Ph.D., Department of Dermatopathology, CHU Sart Tilman, B-4000 Liège, Belgium, or e-mail: af.nikkels@chu.ulg.ac.be. 
with increasing frequency in apparently immunocompetent children $(20,21,33,34)$. Neonatal shingles may occur following maternal varicella during pregnancy $(35,36)$.

Childhood zoster has two recognized risk factors: maternal varicella during the second trimester of pregnancy (21) and varicella during the first year of life $(33,34)$. These two conditions probably do not lead to long-lasting anti-VZV immunity. Whether other risk factors exist is unknown, although other events could potentially lead to inadequate host immune responses. The disease course is usually mild and lasts $1-3$ weeks $(11,37)$. Zoster-associated pain (ZAP), encompassing prodromal, concomitant, and postherpetic pain, is exceptional in children $(11,30,31,38)$. Although the diagnosis can usually be made on clinical grounds, distinguishing it from zosteriform herpes simplex virus (HSV) infection may be difficult (11).

Since controversies persist about herpes zoster risk factors, disease course, and diagnostic procedures, we performed a 2-year prospective study on the natural history of herpes zoster in children.

\section{PATIENTS AND METHODS}

Over a 2-year period, 18 cases of presumptive childhood herpes zoster were clinically identified in a dermatology outpatient setting. Patient ages ranged from 2 to 11 years. Dermatomal distribution, systemic signs (including headache, fever, and adenopathy), any underlying disease, and ZAP were recorded. Evidence of previous varicella and the approximate number of lesions were also recorded. Blood samples for serologic determination of anti-VZV $\operatorname{IgM}$ and $\operatorname{IgG}$ antibodies $(n=10)$, Tzanck smears $(n=18)$, and skin biopsy specimens $(n=4)$ were collected after parental permission was obtained. Immunohistochemical detection of VZV major envelope glycoprotein gE and HSV 1 and 2 was performed on smears and biopsy specimens using a previously reported method (39). The cytologic, histologic, and immunohistochemical results were compared to data gathered on adult shingles (39).

\section{RESULTS}

Childhood herpes zoster was clinically suspected in one immunocompromised child and 17 immunocompetent children. VZV gE was evidenced in multinucleated cells in 16 of 18 smears. One other child had positive immunoreactivity for HSV 1 . One smear was not included because it lacked epithelial cells. The corresponding biopsy specimen showed immunoreactivity for VZV. In the four skin samples, VZV gE was demonstrated in epidermal and infundibular keratinocytes, and in some dermal dendritic cells as well. The cytologic and histologic features, as well as the distribution pattern of VZV on smears and biopsy specimens were indistinguishable from those of infected adults. No cross-reactivity between anti-VZV gE and anti-HSV 1 and 2 antibodies was observed.

Table 1 summarizes the salient clinical features of the 17 immunocompetent children with herpes zoster. The immunocompromised child had recurrent herpes zoster in different dermatomes during a 15-month follow-up. $\mathrm{He}$ is described below.

\section{RECURRENT HERPES ZOSTER}

A 5-year-old boy had idiopathic thrombocytopenic purpura (ITP) for 3 years. He had episodes of recurrent herpes labialis. At the age of 3 years he received prophylactic acyclovir (Zovirax 400 suspension, three times a day for 10 days) when varicella was identified in his sister. One month later a serologic clue for varicella in the past (IgG 1/580, IgM negative) was disclosed, although no varicella lesions were recalled by his parents. Herpes zoster developed without ZAP on the left S2 and S3 dermatomes (Fig. 1). VZV gE-laden keratinocytes were identified using immunohistochemistry on a smear (Fig. 2). Anti-HSV 1 and 2 antibodies yielded negative results. Oral acyclovir (Zovirax 400 suspension, five times a day for 7 days) was administered. The lesions resolved after 2 weeks without scarring. Fifteen months later a crop of clustered papulovesicular lesions developed in the C6 dermatome of the right arm. The atypical clinical presentation prompted us to search for viral agents on a skin biopsy specimen and a smear. $\mathrm{VZV}$ gE was evidenced in keratinocytes and multinucleated cells. Immunostaining with anti-HSV 1 and 2 antibodies

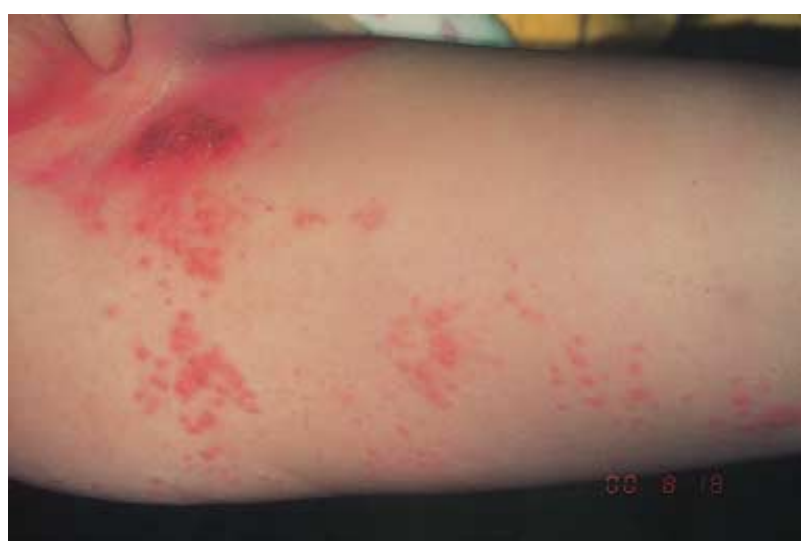

Figure 1. First herpes zoster episode in the $\mathrm{S} 2$ and $\mathrm{S} 3$ dermatomes in a child with idiopathic thrombolytic purpura. 
TABLE 1. Patient Characteristics

\begin{tabular}{rrlllll}
\hline Patient & Age (years) & Dermatome & VZV serology & Varicella lesion number & Varicella shingles interval (years) & Zoster-associated pain \\
\hline 1 & 7 & T8, T9 & IgG+, IgM- & Few & 3 & - \\
2 & 4 & S2, S3 & IgG+ & $?$ & $?$ & - \\
& 5 & C6 & IgM- & $?$ & $?$ & - \\
3 & 5 & T10 & IgG+, IgM- & $?$ & $?$ & + \\
4 & 11 & T10 & IgG+, IgM- & $?$ & $?$ & - \\
5 & 9 & T1, T2 & ND & Few & 6 & - \\
6 & 7 & T4, T5 & ND & Many & 4 & - \\
7 & 7 & L2, L3 & IgG+, IgM- & $?$ & $?$ & - \\
8 & 15 & L3 & ND & Many & 10 & - \\
9 & 9 & T7, T8 & IgG+, IgM- & $?$ & 4 & - \\
10 & 6 & T4, T5 & ND & Few & 5 & + \\
11 & 8 & V3 & IgG+, IgM- & Many & 6 & - \\
12 & 2 & T2, T3 & ND & Few & 2 & - \\
13 & 4 & T8 & IgG+, IgM- & Many & 2 & - \\
14 & 3 & T4 & ND & Many & $?$ & - \\
15 & 8 & T10 & IgG+, IgM- & $?$ & 3 & - \\
16 & 8 & L2 & ND & Many & 4 & - \\
17 & 7 & S2, S3 & IgG+, IgM- & Many & & - \\
\end{tabular}

+, positive; -, negative; ?, no recall of varicella; C, cervical; L, lumbar; ND, not done; S, sacral; T, thoracic; V, trigeminal, VZV, varicella zoster virus.

yielded negative results. Again, ZAP was not noted. Serum anti-VZV IgG positive and IgM negative were still present. Oral acyclovir (Zovirax 400 suspension, five times a day for 7 days) was given and the eruption cleared after 10 days without scarring.

\section{HERPES ZOSTER IN IMMUNOCOMPETENT CHILDREN}

In our series of 17 immunocompetent children, the mean ages of occurrence of varicella and shingles were 3 and 7.3 years, respectively. The interval between varicella and shingles ranged from 1 to 10 years (mean 4.3 years) (Table 1). The duration of the herpes zoster eruption ranged from 7 to 21 days. Involvement of the thoracic dermatomes was observed most frequently (in 11 of 17 patients). One or two dermatomes were involved, but no

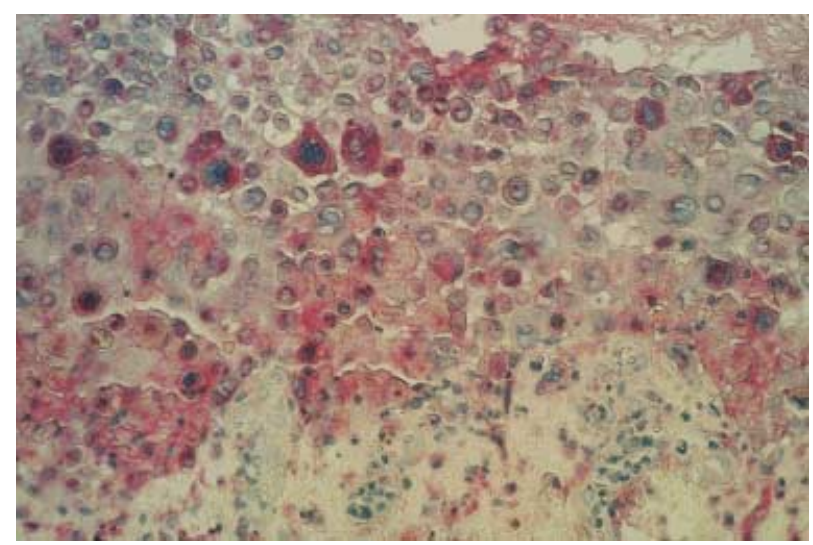

Figure 2. VZV immunoreactivity in keratinocytes (red signal). further extension took place. The disease was mild in all children. Systemic symptoms, underlying malignancies, and other diseases were not detected. Two children experienced mild pain during the eruption, without requiring specific therapy, however. Prodromal and postherpetic neuralgia were not reported. No cutaneous sequelae or complications were detected. All serologic samples revealed the VZV IgM-negative and IgG-positive status, indicating past varicella infection. However, the parents of six children did not recall a history of varicella, although other children in their families had clinical signs of varicella. Skin examination did not reveal typical varicella scars. In 4 other children, varicella had been very mild, exhibiting only a few skin lesions. One of the children received gamma globulins during childhood. Two children, having a cancer-treated brother, had received prophylactic oral acyclovir after having been in contact with other varicella-afflicted children. One of them developed attenuated varicella and the other did not have any clinical sign of varicella.

\section{DISCUSSION}

Our series of 17 cases of herpes zoster in immunocompetent children diagnosed over a 2 -year period in an outpatient dermatology unit seems to outnumber in frequency the 21 cases recorded over a 3 -year period in a larger hospital inpatient setting (11). These findings are in line with the progressive increase in the incidence of herpes zoster in otherwise healthy children over the past decades $(20,21,33,34,40-42)$. However, it is possible that some herpes zoster cases were misdiagnosed in the past when specific laboratory investigations were not 
available. Indeed, the clinical distinction between HSV and VZV infections is not always reliable. In our series, one child had a zosteriform HSV infection.

In another series of 26 children with putative herpes zoster, 5 cases were demonstrated by immunofluorescence to be zosteriform HSV infections (11). Other studies indicate that $4-20 \%$ of the HZ-like presentations correspond to misdiagnosed HSV infections $(43,44)$. These results confirm the importance of immunohistochemical identification on smears or skin biopsy specimens to distinguish herpes zoster from zosteriform HSV infection. Furthermore, these methods are also helpful in the diagnosis of unusual presentations (45-47), as illustrated by the second herpes zoster episode in our immunocompromised patient. No cross-reactivities were evidenced between anti-HSV and anti-VZV antibodies.

Some reports exist of recurrent herpes zoster in adult patients $(40-42)$, but to our knowledge, this is the first report of recurrent childhood herpes zoster. Underreporting of such cases is possible because they may be clinically misdiagnosed as HSV infection and not investigated further.

One report claimed that herpes zoster in otherwise healthy children was more severe than in adults (12). However, the indolent disease course in our series of patients is in line with what most other publications report $(9,11-25,37-39)$. The absence of ZAP is the most striking clinical difference compared to adult herpes zoster. We confirmed the frequent involvement of two dermatomes, without any further extradermatomal lesions, and the preferential thoracic location of the lesions (9,11-25,37-39). No systemic reactions such as fever, headache, or regional lymphadenopathy were recorded, in contrast to another report (39). The absence of underlying diseases confirms that childhood herpes zoster is not a paraneoplastic marker (30). Complications of herpes zoster in children without underlying disease may include aseptic meningitis (12), facial palsy $(12,16)$, and cutaneous dissemination $(12,16,22)$. In our patients, no zoster-associated complications were noted, thus confirming other reports (9,11-25,37-39).

Epidemiologic studies indicate that maternal varicella during pregnancy and varicella during the first year of life represent risk factors for developing herpes zoster during childhood. In the first situation, the maternal antiVZV antibodies and the immature fetal immune system probably limit the development of a long-lasting antiVZV defense. The relative risk of varicella during the first year of life developing into childhood herpes zoster ranges from 2.8 to $20.9(11,21)$. The specific humoral and cellular anti-VZV immunity appears to be lower in infants younger than 1 year of age compared to older children $(33,34)$. In our series, 7 of 17 children had varicella before the age of 4 years, with only 1 child younger than 1 year. No cases were recorded following maternal varicella during pregnancy.

Our findings suggest that varicella with few clinical lesions, as well as subclinical varicella, prophylactic acyclovir treatment, and the administration of immunoglobulins may also represent risk factors for childhood herpes zoster. Despite awareness that the absent history of varicella in 6 of 17 cases is only based on anamnestic recall, it is unlikely that the families did not recognize full-blown varicella in the children. Subclinical varicella as a risk factor for childhood zoster is further supported by a report of childhood herpes zoster following unnoticed varicella (48).

Our present findings should be evaluated in larger series before drawing firm conclusions. Presently we offer as an hypothesis that a mild or subclinical varicella course is responsible for impaired stimulation of sustained anti-VZV immunity. When a child receiving immunoglobulins is in contact with other children who have varicella, he/she probably escapes full-blown varicella by a steal mechanism linked to the circulating immunoglobulins. Prophylactic acyclovir probably nudges the extension of the primary infection and thus abates specific anti-VZV immunity.

There is no consensus about the use of antiviral drugs in the treatment of shingles in children $(11,46,49,50)$. They are generally not recommended for uncomplicated herpes zoster. However, treatment may be considered in immunocompetent children and adolescents with shingles involving the first branch of the trigeminal nerve $(48,50)$. Antiviral treatment is also indicated in immunocompromised children with herpes zoster who are at risk of higher morbidity, sequelae, and death (11).

In conclusion, childhood herpes zoster is rare, but probably often underrecognized. The classical risk factors were only rarely found in our study. The findings in our series suggest that immunoglobulin treatment and preventive acyclovir use in varicella, as well as subclinical varicella or varicella with few skin lesions represent risk factors for childhood herpes zoster. The clinical course of childhood herpes zoster mimics adult shingles, although it remains mild and ZAP is usually absent. These features do not support routine antiviral treatment for uncomplicated shingles in the otherwise healthy child. The immunohistochemical identification of VZV and HSV on smears or biopsy specimens represents a simple, but helpful diagnostic aid to avoid misdiagnosis and underrecognition of childhood herpes zoster.

\section{REFERENCES}

1. Hope-Simpson RE. The nature of herpes zoster. Proc R Soc Med 1965;58:9-20. 
2. Wharton M. The epidemiology of varicella-zoster virus infections. Infect Dis Clin N Am 1996;10:571-581.

3. Lin F, Hadler JL. Epidemiology of primary varicella and herpes zoster hospitalizations: the pre-varicella vaccine era. J Infect Dis 2000;181:1897-1905.

4. Brunell PA, Miller LH, Lovejoy F. Zoster in children. Am J Dis Child 1968;115:432-437.

5. Feldman S, Hughes WT, Memphis K. Herpes zoster in children with cancer. Am J Dis Child 1973;126:178-184.

6. Reboul F, Donaldson SS, Kaplan HS. Herpes zoster and varicella infections in children with Hodgkin's disease: an analysis of contributing factors. Cancer 1978;41:9599.

7. Skovby F, Sullivan MP. Herpes zoster and varicella in children with Hodgkin's disease. Acta Paediatr Scand 1982;71:269-273.

8. Grose C. Zoster in children with cancer: radioimmune precipitation profiles of sera before and after illness. J Infect Dis 1983;147:47-56.

9. Latif R, Shope TC. Herpes zoster in normal and immunocompromised children. Am J Dis Child 1983; 137:801-802.

10. Kawasaki H, Takayma J, Ohira M. Herpes zoster infection after bone marrow transplantation. J Pediatr 1996; 128:353-356.

11. Kakourou T, Theodoridou M, Mostrou G, Syriopoulou V, Papadogeorgaki H, Constantopoulos A. Herpes zoster in children. J Am Acad Dermatol 1998;39:207-210.

12. Takayama N, Yamada H, Kaku H, Minamitani M. Herpes zoster in immunocompetent and immunocompromised Japanese children. Pediatr Int 2000;42:275-279.

13. McKendrick GD, Raychoudhury SC. Herpes zoster in childhood. Scand J Infect Dis 1972;4:23-25.

14. Rogers RS III, Tindall JP. Herpes zoster in children. Arch Dermatol 1972;106:204-207.

15. Panteliadis CP. Zur Kenntnis des Zoster im Kindesalter. Monatssch Kinderheilk 1973;121:101-104.

16. Kellerer H, Kerl H. Herpes Zoster im Kindesalter Darstellung komplizierter Verlaufsformen. Klin Pediatr 1973; 185:57-63.

17. Myers MG. Varicella and herpes zoster: comparisons in the old and young. Geriatrics 1977;32:77-79.

18. Nagy G, Varga G. Ein Beitrag zur Pathogenese und Topographie des Herpes zoster im Kindes- und Erwachsenenalter. Zeitschr Hautkr 1977;52:691-698.

19. Gupta S, Soodan SS, Pahda SP, Bali FS. Herpes zoster in children. Indian J Ophthal 1979;26:50-51.

20. Hartley WJ, Mandal BK. Herpes zoster in childhood. Practitioner 1982;226:766-768.

21. Baba K, Yabuuchi H, Takahashi M, Ogra PL. Increased incidence of herpes zoster in normal children infected with varicella zoster virus during infancy: community-based follow-up study. J Pediatr 1986;108:372-377.

22. Courter BJ. Pediatric herpes zoster with mild cutaneous dissemination. Pediatr Emerg Care 1993;9:33-35.

23. Guess HA, Broughton DD, Melton LJ III, Kurland LT. Epidemiology of herpes zoster in children and adolescents: a population-based study. Pediatrics 1985;76:512517.

24. Papadopoulos AJ, Birnkrant AP, Schwartz RA, Janniger CK. Childhood herpes zoster. Cutis 2001;68:21-23.

25. Socan M. Herpes zoster in non-hospitalized children. Clin Microbiol Infect 2001;7:91-93.
26. Taki M, Inamochi H. Incidence of herpes zoster in infancy in Japan. Acta Pediatr Jpn 1991;33:57-60.

27. Funaki B, Elpern DJ. Herpes zoster incidence in younger age groups. J Am Acad Dermatol 1987;16:883-884.

28. Brunell PA, Taylor-Wiedeman J, Geiser CF, Frierson L, Lydick E. Risk of herpes zoster in children with leukemia: varicella vaccine compared with history of chickenpox. Pediatrics 1986;77:53-56.

29. Novelli VM, Brunell PA, Geiser CF, Narkewics S, Frierson L. Herpes zoster in children with acute lymphocytic leukemia. Am J Dis Child 1988;142:71-72.

30. Petursson G, Helgason S, Gudmundsson S, Sigurdsson JA. Herpes zoster in children and adolescents. Pediatr Infect Dis J 1998;17:905-908.

31. Smith CG, Glaser DA. Herpes zoster in childhood: case report and review of the literature. Pediatr Dermatol 1996; 13:226-229.

32. Meister W, Neiss A, Gross G, et al. Demography, symptomatology, and course of disease in ambulatory zoster patients. A physician-based survey in Germany. Intervirology 1998;41:272-277.

33. Terada K, Kawano S, Yoshihiro K, Morita T. Characteristics of herpes zoster in otherwise normal children. Pediatr Infect Dis J 1993;12:960-961.

34. Terada K, Tanaka H, Kawano S, Kataoka N. Specific cellular immunity in immunocompetent children with herpes zoster. Acta Paediatr 1998;87:692-694.

35. Querol I, Bueno M, Cebrian A, Gonzalez-Echeverria FJ. Connatal herpes zoster. Cutis 1996;58:231-234.

36. Mogami S, Muto M, Mogami K, Asagami C. Congenitally acquired herpes zoster infection in a newborn. Dermatology 1997; 194:276-277.

37. Tereda K, Kawano S, Yoshihiro K, Morita T. Varicella zoster virus (VZV) reactivation is related to the low response of VZV specific immunity after chickenpox in infancy. J Infect Dis 1994;169:650-652.

38. Wurzel CL, Kahan J, Heitler M, Rubin LG. Prognosis of herpes zoster in healthy children. Am J Dis Child 1986;140:477-478.

39. Nikkels AF, Debrus S, Sadzot-Delvaux C, Piette J, Rentier $\mathrm{B}$, Piérard GE. Immunohistochemical identification of varicella zoster virus gene 63 encoded (IE63) and late (gE) proteins on smears and cutaneous biopsies. J Med Virol 1995;47:342-347.

40. Leurer J. A case of recurrent herpes zoster. Br J Dermatol 1957;69:282-283.

41. Heskel NS, Hanifin JM. "Recurrent herpes zoster": an unproved entity? J Am Acad Dermatol 1984;10:486-490.

42. Bansal R. Recurrent herpes zoster. Int J Dermatol 2001;40:542-543.

43. Kalman CI, Laskin OL. Herpes zoster and zosteriform herpes simplex virus infections in immunocompetent adults. Am J Med 1986;81:775-778.

44. Tyring S, Barbarash RA, Nahlik JE, et al. Famciclovir for the treatment of acute herpes zoster: effects on acute disease and postherpetic neuralgia. Ann Intern Med 1995; 123:89-96.

45. Sauerbrei A, Eichhorn U, Schacke M, Wutzler P. Laboratory diagnosis of herpes zoster. J Clin Virol 1999;14:31-36.

46. Nikkels AF, Piérard GE. Recognition and treatment of shingles. Drugs 1994;48:528-548.

47. Van Praag MCG, Van Rooij RWG, Folkers E, Spritzer R, Menke HE, Oranje AP. Diagnosis and treatment of 
pustular disorders in the neonate. Pediatr Dermatol 1997;14:131-143.

48. Lagarde C, Steen AE, Bieber T, Steen KH. Zoster in childhood after inapparent varicella. Acta Derm Venereol (Stockh) 2001;81:212-213.
49. Arvin AM. Management of varicella-zoster virus infections in children. Adv Exp Med Biol 1999;458:167-174.

50. Rothe M, Feder H, Grant-Kels J. Oral acyclovir therapy for varicella and zoster infections in pediatric and pregnant patients: a brief review. Pediatr Dermatol 1991;8:236-242. 